\title{
Strategies for Isothermal Amplification of Nucleic Acids: are they Ready to be Applied in Point of Care Diagnosis of Mycosis?
}

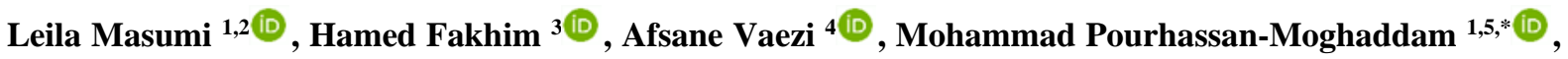 \\ Abbas Ebrahimi-Kalan 6 (iD), Nosratollah Zarghami 1,* (i) \\ 1 Department of Medical Biotechnology, Faculty of Advanced Medical Sciences, Tabriz University of Medical Sciences, \\ Tabriz, Iran \\ 2 Student Research Committee, Tabriz University of Medical Sciences, Tabriz, Iran \\ 3 Infectious Diseases and Tropical Medicine Research Center, Isfahan University of Medical Sciences, Isfahan, Iran \\ 4 Department of Medical Mycology, School of Medicine, Mazandaran University of Medical Sciences, Sari, Iran \\ 6 Department of Neuroscience and Cognition, Faculty of Advanced Medical Sciences, Tabriz University of Medical \\ Sciences, Tabriz, Iran \\ * Correspondence: zarghami@tbzmed.ac.ir, pourhassanm@tbzmed.ac.ir, pourhassanmo@gmail.com;
}

Scopus Author ID 55181898000

Received: 19.09.2020; Revised: 25.10.2020; Accepted: 28.10.2020; Published: 1.11.2020

\begin{abstract}
The early detection of invasive fungal infection (IFD) is significant in order to decrease mortality in susceptible patients. There is, therefore, a need for sensitive and specific fungal species detection assays in a clinical laboratory for early targeted therapy. The isothermal amplification method may be useful for the screening of fungal isolates, especially in resource-poor settings. Therefore, our aim was to review the isothermal nucleic acid amplification methods and their applications in fungal pathogen detection. Out of 50 reported studies, 28, 12, 6, 2, and 2 studies used the isothermal-based assays of a loop-mediated isothermal amplification (LAMP), nucleic acid sequence-based amplification (NASBA), rolling circle amplification (RCA), multiple displacement amplification (MDA) and polymerase Spiral Reaction (PSR), respectively. Thirty-two studies used clinical samples, 18 pure culture, and four environmental samples. The diagnostic accuracy of isothermal nucleic acid amplification testing for pathogenic fungal was reported as high (sensitivity $0.89-1.0$ and specificity 0.63-1.0) in all studies irrespective of the sample tested. Although the isothermal-based assays showed high sensitivity and specificity in reported studies, it is still poorer than that of PCR assays. However, improving the assay to make it simpler, more effective, and inexpensive compared with newer PCR methods are still needed.
\end{abstract}

Keywords: Isothermal Molecular Diagnostics; Invasive fungal infection; Precision testing; Simple detection.

(C) 2020 by the authors. This article is an open-access article distributed under the terms and conditions of the Creative Commons Attribution (CC BY) license (https://creativecommons.org/licenses/by/4.0/).

\section{Introduction}

Fungi are ubiquitous microorganisms, which increasingly are recognized as emerging opportunistic pathogens of clinical relevance due to their high morbidity and mortality infection rate among immunocompromised individuals and other highly susceptible patients $[1,2]$. Invasive fungal diseases (IFD) [3] are one of the major causes of morbidity and mortality among populations at high risk, including those with corticosteroid therapy, uncontrolled diabetes, solid organ or allogeneic stem cell transplant recipients, and patients undergoing immunosuppressive therapies [2,4]. The global reported incidence of chronic pulmonary 
aspergillosis is 3,000,000 cases; invasive aspergillosis is $~ 250,000$ cases; invasive candidiasis is $~ 700,000$ cases; and cryptococcal meningitis in human immunodeficiency virus (HIV)infected patients is $\sim 223,100$ cases annually $[3,5,6]$. The gold standard for diagnosing IFD is based on histopathological and mycological findings, followed by radiologic manifestations [3]. The patients suspected of IFD should be immediately treated in order to improve the clinical outcomes [7]. Despite our improved understanding of IFD and the availability of new antifungal treatment, the survival rate in IFD remains poor $[8,9]$. The detection of the IFD case in the early days of infections is critical for minimizing the mortality rate in susceptible patients $[10,11]$. There is, therefore, an urgent need for sensitive and specific fungal species detection assays in a clinical laboratory for early targeted therapy. Molecular diagnostics have shown advantages in the clinical diagnostic laboratory for routine detection, epidemiologic, and fingerprinting analysis of fungal infections [2, 12-14]. Molecular diagnostics reduce the time required for the morphology and biochemistry identification, including the selection of fungal culture media and the incubation period $[2,12]$. This diagnostic method can be used to detect fungal isolates directly from clinical specimens [15], which reduces the exposure to the possible infection agents present in the patient samples. Current development in a polymerase chain reaction (PCR) has led to the advancement of newer molecular amplification methods which isothermal amplification methods are considered one of the most important classes of molecular diagnostic methods [16]. Considering the successful applications of isothermal amplifications in many fields of diagnostics, isothermal amplification methods may be useful for screening of fungal isolates, especially in resource-poor settings or for point-of-care testing [17]. Therefore, our aim was to review the current state of the art in isothermal nucleic acid amplification methods and their applications in fungal pathogen detection.

\section{Materials and Methods}

\subsection{Study design.}

The review process involved the study of existing published literature of all reported published papers based on isothermal nucleic acid amplification identification of pathogenic fungi until January 2020.

\subsection{Search strategy.}

To search the published literature, Medline database through PubMed, Embase through Scopus, ISI Web of Science, Science Direct, and Google Scholar were used to retrieve the fulltext of articles of isothermal nucleic acid amplification identification of pathogenic fungi using the key words "DNA amplification", " polymerase chain reaction" or "PCR", "isothermal nucleic acid amplification", "loop-mediated isothermal amplification" or "LAMP', "nucleic acid sequence-based amplification" or "NASBA", "rolling circle amplification", or "RCA', "helicase-dependent amplification" or "HDA", "strand displacement amplification" or "SDA", "multiple displacement amplification" or "MDA" and "polymerase Spiral Reaction", or "PSR", "fungal detection method", or "molecular diagnosis", “fungal infection', “fungal”, “yeast', “Candida albicans", "Aspergillus fumigatus" and "pathogenic fungi"' in different combinations. A total of 52 relevant articles were returned using these keywords. All references were compiled into a database and managed using EndNote Library version X9.

\subsection{Data extraction.}


The data was organized in master sheets, which were separated for each paper. The following data items were collected: amplification method, samples, genus and species of fungal, detection method, assay type, target, test duration, limitation of detection, and specificity of each method.

\section{Results and Discussion}

We retrieved 123 published articles, which yielded 52 papers included in this review. Ten, nine, and six were from Japan, China, and Germany, respectively; three were from each of Brazil, The Netherlands, Korea, Australia, and Iran; two were from each of Portugal, USA, and France, and one was from each of Italy, UK, New Zealand, and India. Among the 52 studies, 36 used the cohort approach, five used the case-control approach, and nine did not describe the recruitment approach. Analysis of the total 52 papers included in this review was done based on the following aspects: amplification method, samples, genus and species of fungal, detection method, assay type, target, test duration, limitation of detection, and specificity of each method. (Table 1) [18-70]. Thirty-three studies used clinical samples, 19 pure culture, and four environmental samples. In addition, 29, 12, 7, 3, and 2 studies used the isothermal-based assays of LAMP, NASBA, RCA, MDA, and PSR, respectively. The diagnostic accuracy of isothermal nucleic acid amplification testing for pathogenic fungal was reported as high (sensitivity $0.89-1.0$ and specificity $0.63-1.0$ ) in all studies irrespective of the sample tested (pure culture, clinical and environmental samples). Two of the studies provided diagnostic accuracy on NASBA testing for Aspergillus and Candida species in blood specimens of patients suffering from invasive aspergillosis and candidiasis [46, 71]. Paracoccidioides brasiliensis, Histoplasma capsulatum, Candida species, Saccharomyces species, Aspergillus species, Trichosporon species, Cryptococcus neoformans, Penicillium marneffei, Pneumocystis jirovecii, Fonsecaea species, and Fusarium species were identified using isothermal amplification-based techniques in these studies. The sensitivity of LAMP testing for Candida auris was reported as high in the Yamamoto et al. . [26] investigation $(2 \times$ $10^{1}$ copies per reaction). Candida species was the most frequently detected pathogen among blood samples $(\mathrm{n}=55)$, and sensitivity for Candida species detection by NASBA and PSR was 1-100 CFU/ml and $6.9 \mathrm{pg} / \mathrm{ml}$, respectively, with a specificity of 100\%. All LAMP reactions were completed within $60 \mathrm{~min}$ from start to finish per clinical sample. The most common target genes used in these 50 studies were the ITS gene in 16 studies and $18 \mathrm{~S}$ rDNA in 13 studies. A comparative study of isothermal-based assays employing primers targeting $18 \mathrm{~S}$ rRNA and ITS genes revealed a similar limit of detection for both genes.

Although newer DNA amplification methods have the potential to considerably influence the diagnosis of fungal infectious diseases [2], the performance of a molecular assay is generally more expensive than conventional diagnostic laboratory methods. Conventional diagnostic/identification methods require a minimum of $24 \mathrm{~h}$, and in various cases, significantly longer. Some fungal species causing human infections, such as Scedosporium species [72], Malassezia species [73], and Mucorales [74], are not easily detected by routine culture methods and require specialized procedures. In the reported studies, the isothermal amplification-based techniques provided the summary estimate sensitivity of 89-100\% and specificity of $63-100 \%$. Our results were supported by some factors. First, the strength of the current study is that we considered diagnostic assay focusing on isothermal amplification and pathogenic fungal. Second, we carried out an attentive study search and included as many as 50 studies. Third, sensitivity analyses consistently in reported studies revealed similar overall 
diagnostic ability among different isothermal-based assays. Alternative isothermal amplification-based methods such as LAMP is available for the detection of fungal pathogens [18]. LAMP is relatively sensitive, specific, and cost-effective [17, 75]. Furthermore, numerous isothermal amplification-based methods have recently emerged in the field of fungal pathogen detection due to their cost-effectiveness and rapidness $[2,15]$. The potential benefits of earlier diagnosis methods of an invasive fungal infection include the timely initiation of appropriate antifungal therapy, which may prevent progressive tissue invasion, lead to decreased mortality, and an overall improvement in healthcare utilization and anti-antifungal stewardship [76]. If isothermal amplification testing for the fungal pathogen is to be used as a rapid tool, further studies are required to demonstrate the safety of this approach. The isothermal-based assays combined with conventional methods may be an acceptable diagnostic strategy, especially in resource-poor countries. A combination of several rapid methods for the detection of a particular fungal pathogen can also be possible as the use of only one detection test may not be sufficient to confirm the identified fungal pathogen [77]. The effect of different combinations of rapid methods for fungal human pathogen detection in order to develop the most effective and accurate detection method would be considered. The overall sensitivity of isothermal testing is high, but the existing studies using blood and clinical samples are small. In the future, it should be focused on other clinical sample types, e.g., urine, stool, blood, plasma, serum, CSF, BAL, and throat swabs, to test the clinical application of the fungal species-isothermal amplification assay in diverse samples [78]. In conclusion, we conducted a review study to reveal the use of the isothermal amplification assay in the diagnosis of fungal species causing human infections. Although the isothermal-based assays showed very good sensitivity and specificity in reported studies, they still needed to be improved to become simpler, more effective, and cheaper compared with PCR-based methods.

\section{Conclusions}

There are a variety of studies to detect fungal infection, and it has to be selected the optimal diagnostic/identification tools according to the prevalence of a fungal infection in the area in patients suspected of IFD. However, cost issues concerning the diagnostic strategy should be considered. Although PCR methods are the best examinations currently available [79-82], isothermal amplification-based techniques may be considered as an alternative test in resource-poor and developing countries. Isothermal amplification testing can be performed in $1 \mathrm{~h}$ [70], and it could be used prior to initiation of antifungal therapy. The overall sensitivity of isothermal testing is high, but the existing studies using blood and clinical samples are small. In the future, it should be focused on other clinical sample types, e.g., urine, blood, CSF, BAL, and throat swabs, to test the clinical application of the fungal species-isothermal amplification assay in diverse samples. In conclusion, we conducted a review study to reveal the use of the isothermal amplification assay in the diagnosis of fungal species causing human infections. Although the isothermal-based assays showed very good sensitivity and specificity in reported studies, they still needed to be improved to become simpler, more effective, and inexpensive compared with PCR-based methods, especially for using them in point of care diagnosis. 
Table 1. Employed isothermal nucleic acid amplification technologies for the diagnosis of pathogenic fungi.

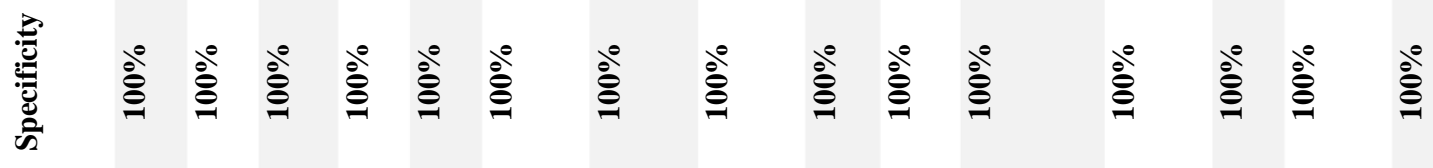

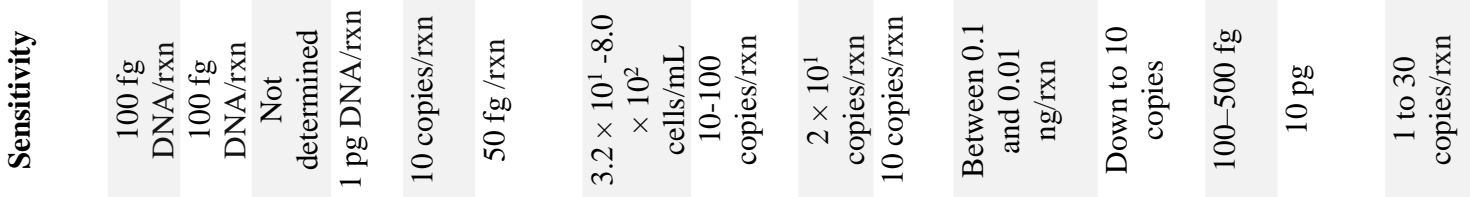

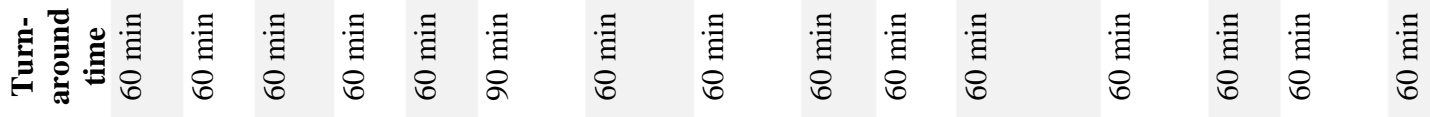

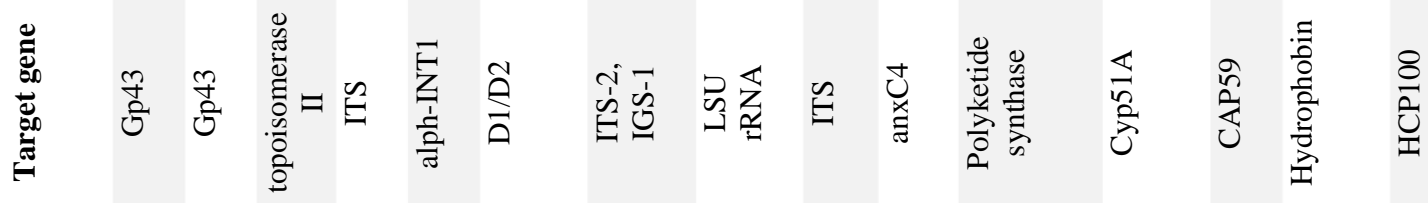

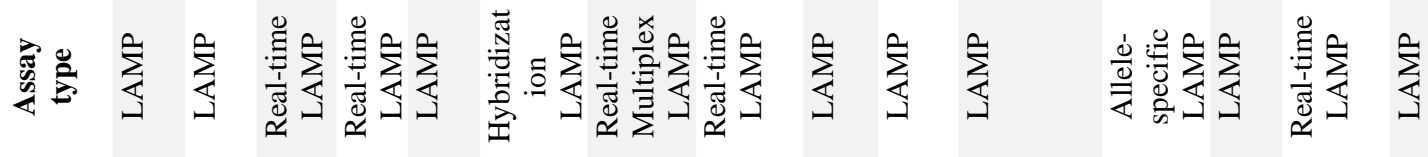

II

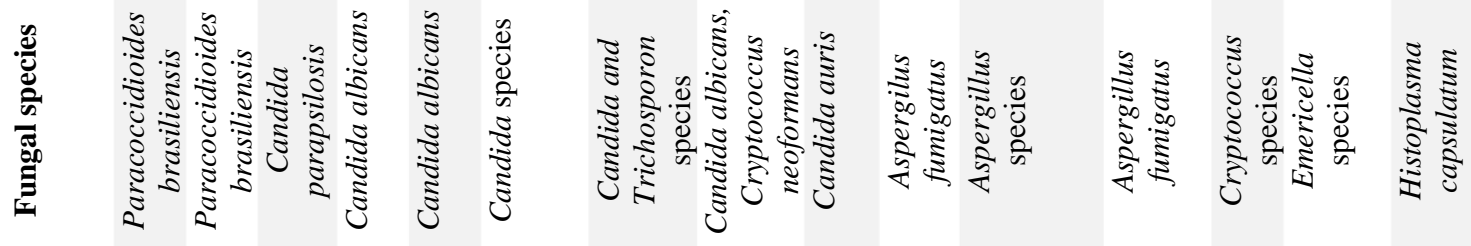

HIIn

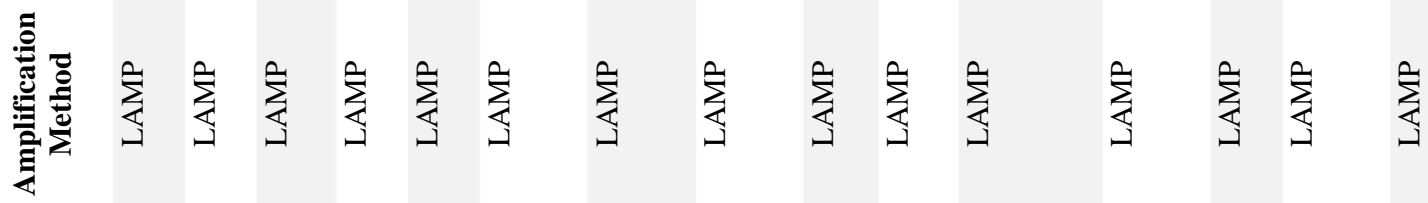

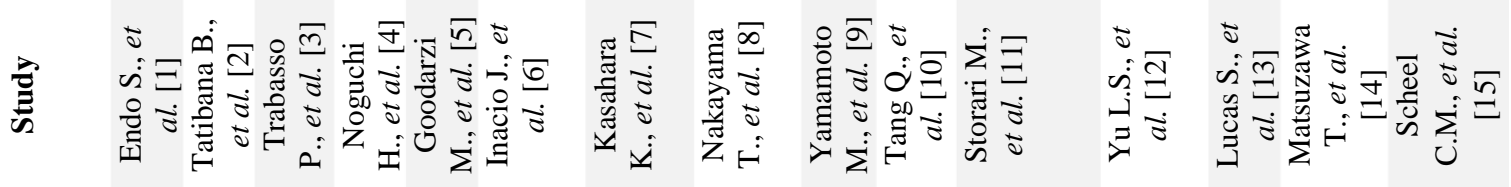

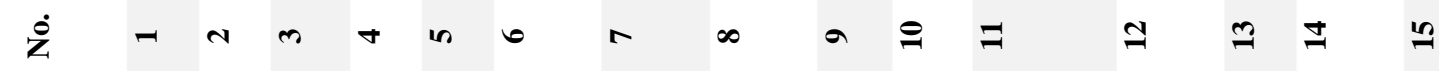




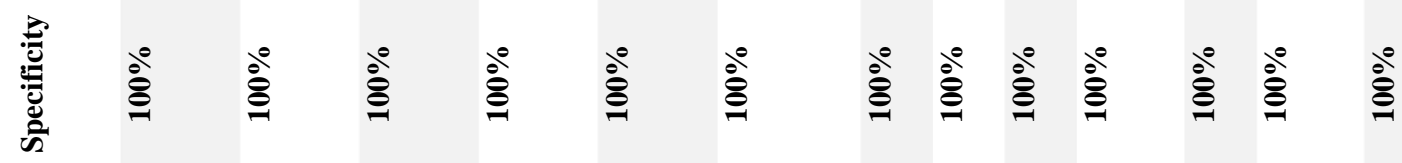

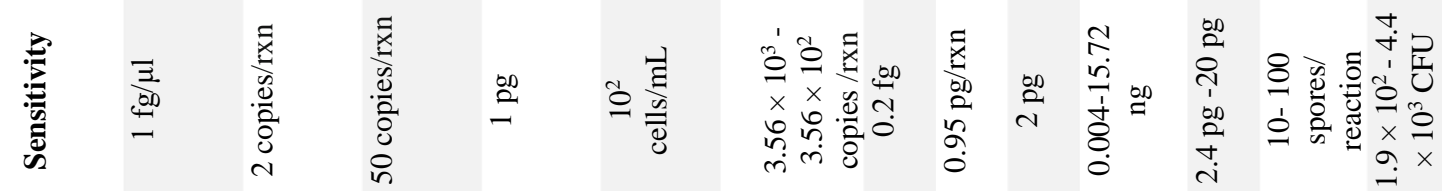

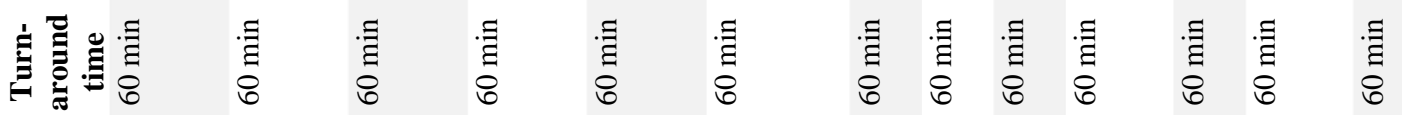

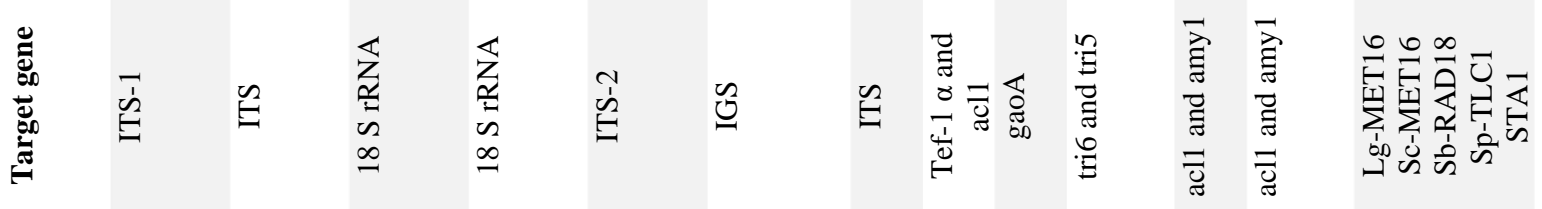

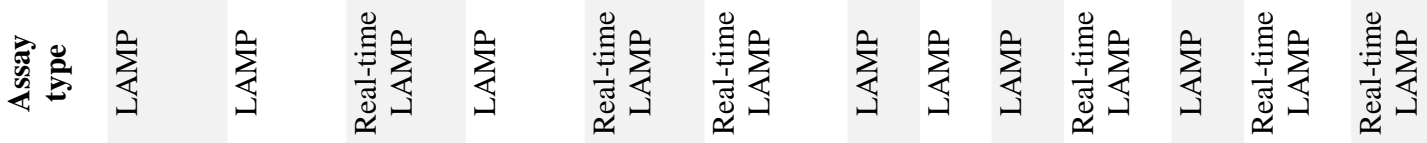

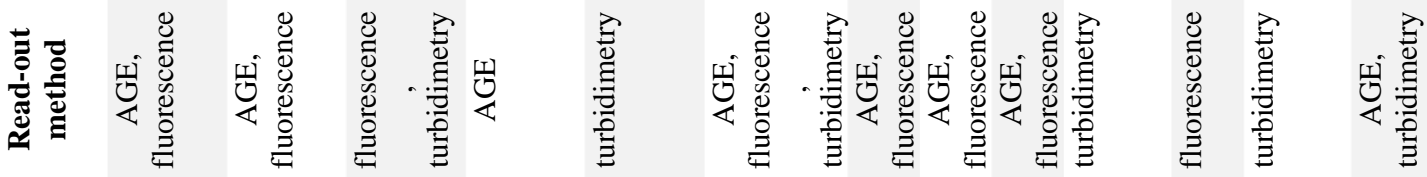

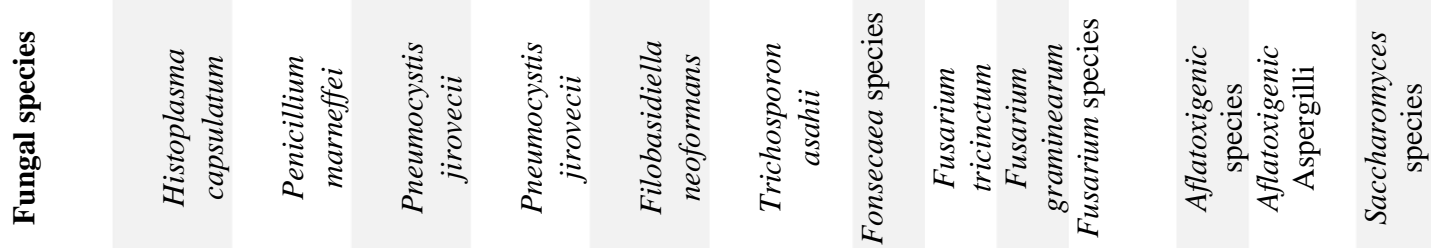

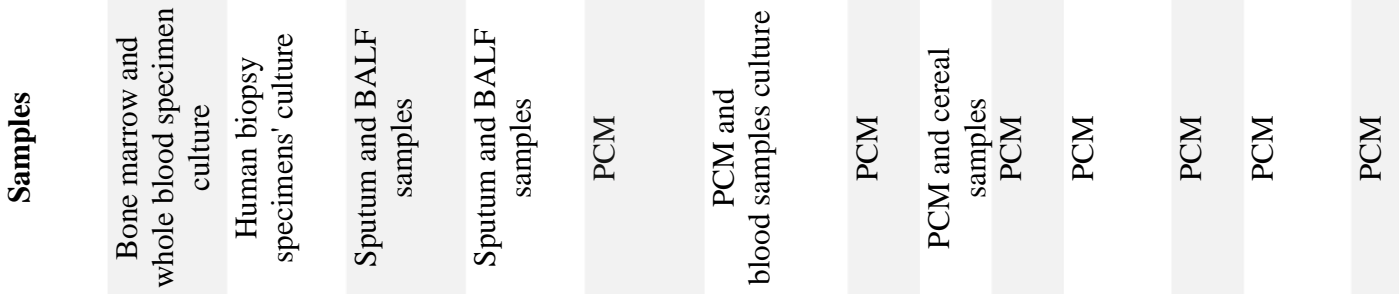

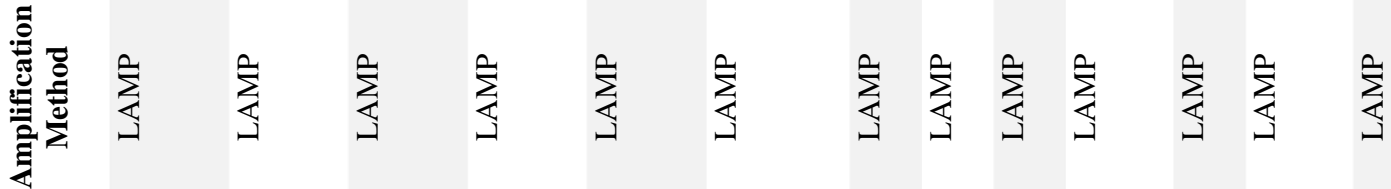

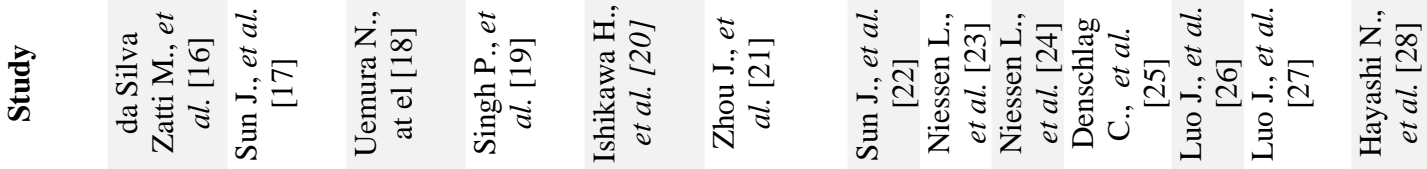

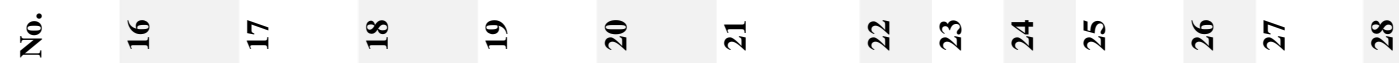




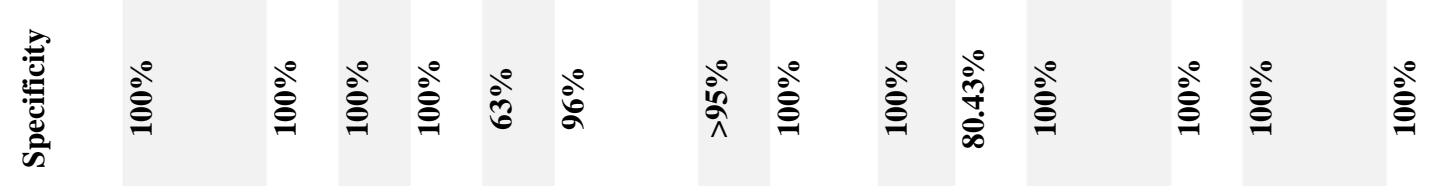

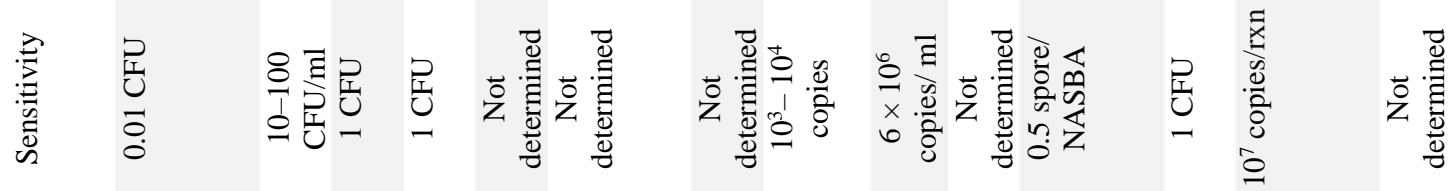

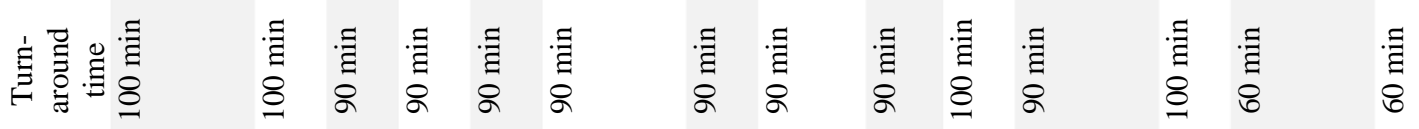

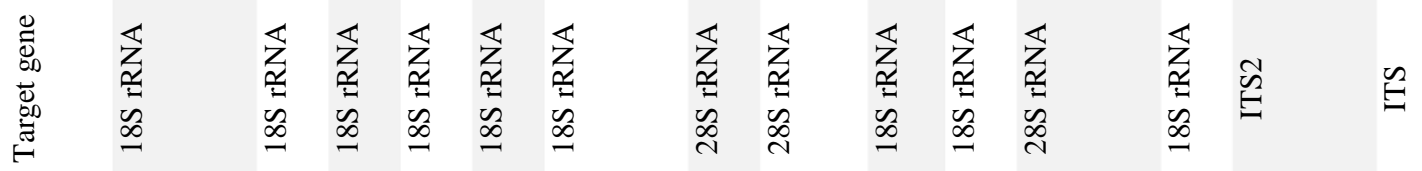

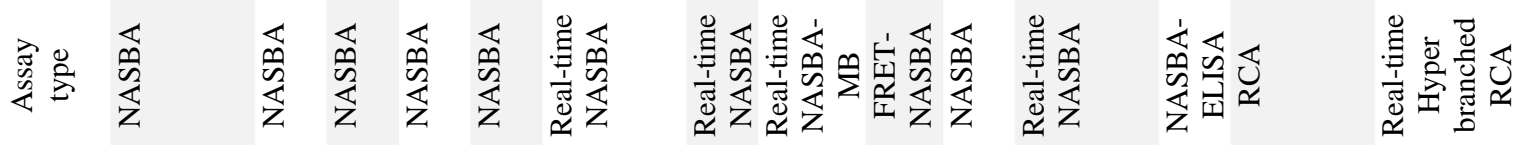

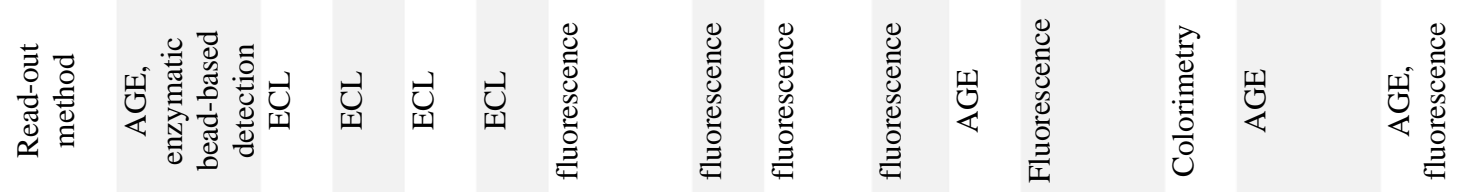

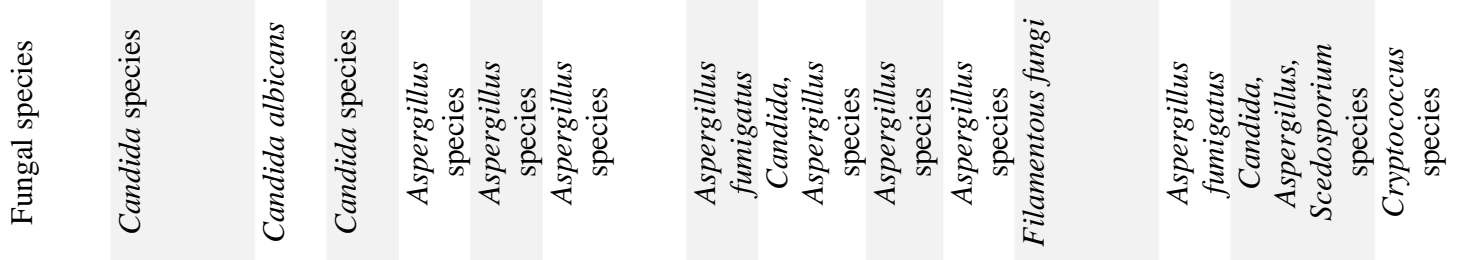

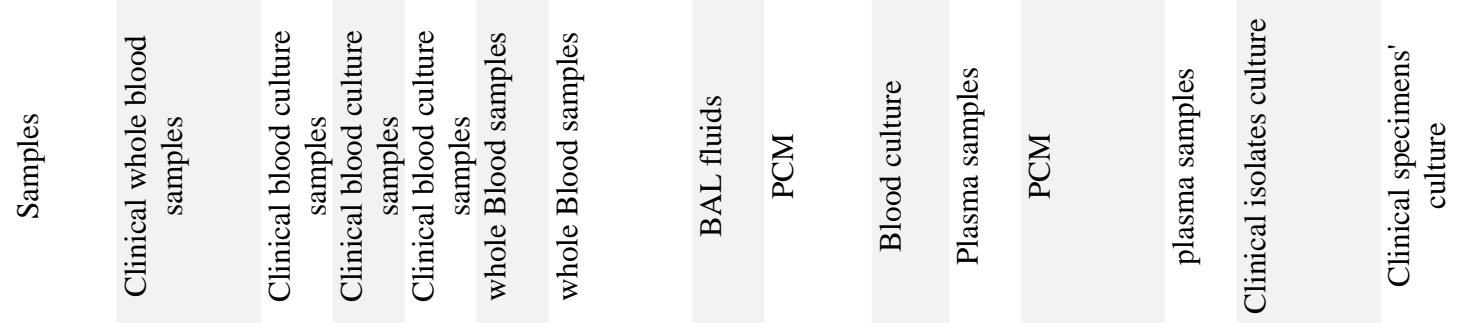

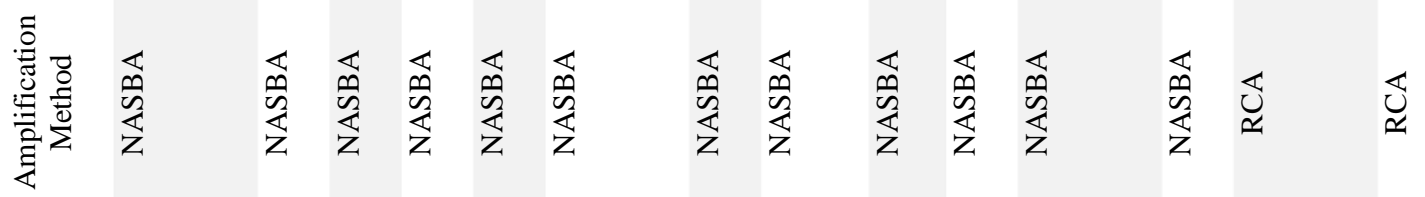

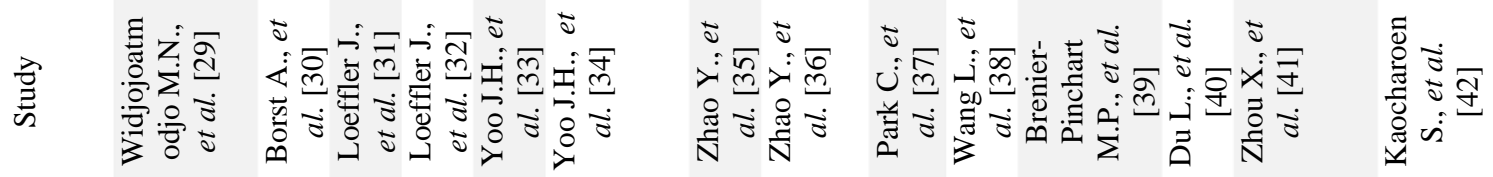

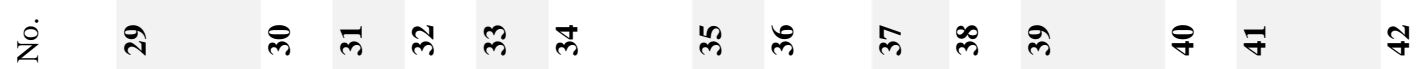




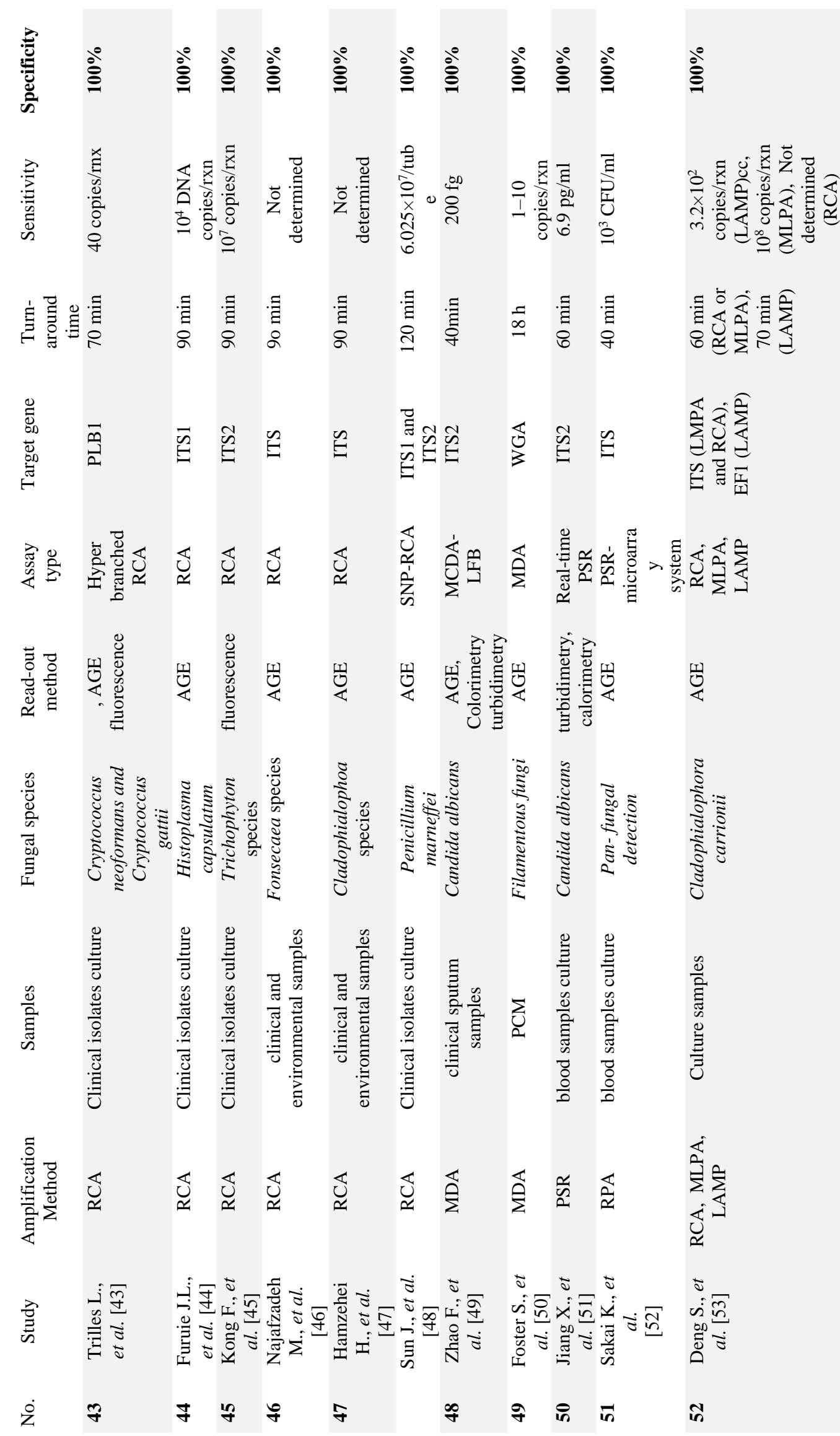

LAMP: Loop-mediated isothermal amplification, NASBA: Nucleic acid sequence-based amplification, RCA: Rolling circle amplification, RPA: Recombinase polymerase amplification, MDA: Multiple displacement amplification, FRET: fluorescence resonance energy transfers cycling probe technology, PSR: Polymerase Spiral Reaction, ITS: internal transcribed spacer region in ribosomal RNA gene, IGS: intergenic spacer separating ribosomal RNA gene repeats, AGE: Agarose gel electrophoresis, PCM: pure culture mycelium, BALF: bronchoalveolar lavage fluid, ECL: electrochemiluminescence, SNP: Single Nucleotide Polymorphism. 


\section{Funding}

This research received no external funding.

\section{Acknowledgments}

This article has been extracted from the MSc thesis grant number "59060". The authors would like to thank the research deputy of Tabriz University of Medical Sciences for their financial support.

\section{Conflicts of Interest}

The authors declare no conflict of interest.

\section{References}

1. Richardson, M.; Lass-Flörl, C. Changing epidemiology of systemic fungal infections. Clin Microbiol Infect 2008, 14, 5-24, https://doi.org/10.1111/j.1469-0691.2008.01978.x.

2. Wickes, B.L.; Wiederhold, N.P. Molecular diagnostics in medical mycology. Nat Commun 2018, 9, https://doi.org/10.1038/s41467-018-07556-5.

3. Donnelly, J.P.; Chen, S.C.; Kauffman, C.A.; Steinbach, W.J.; Baddley, J.W.; Verweij, P.E.; Clancy, C.J.; Wingard, J.R.; Lockhart, S.R.; Groll, A.H.; Sorrell, T.C.; Bassetti, M.; Akan, H.; Alexander, B.D.; Andes, D.; Azoulay, E.; Bialek, R.; Bradsher, R.W.; Bretagne, S.; Calandra, T.; Caliendo, A.M.; Castagnola, E.; Cruciani, M.; Cuenca-Estrella, M.; Decker, C.F.; Desai, S.R.; Fisher, B.; Harrison, T.; Heussel, C.P.; Jensen, H.E.; Kibbler, C.C.; Kontoyiannis, D.P.; Kullberg, B.J.; Lagrou, K.; Lamoth, F.; Lehrnbecher, T.; Loeffler, J.; Lortholary, O.; Maertens, J.; Marchetti, O.; Marr, K.A.; Masur, H.; Meis, J.F.; Morrisey, C.O.; Nucci, M.; Ostrosky-Zeichner, L.; Pagano, L.; Patterson, T.F.; Perfect, J.R.; Racil, Z.; Roilides, E.; Ruhnke, M.; Prokop, C.S.; Shoham, S.; Slavin, M.A.; Stevens, D.A.; Thompson, G.R.; Vazquez, J.A.; Viscoli, C.; Walsh, T.J.; Warris, A.; Wheat, L.J.; White, P.L.; Zaoutis, T.E.; Pappas, P.G. Revision and Update of the Consensus Definitions of Invasive Fungal Disease From the European Organization for Research and Treatment of Cancer and the Mycoses Study Group Education and Research Consortium. Clin Infect Dis 2019, https://doi.org/10.1093/cid/ciz1008.

4. Gavaldà, J.; Meije, Y.; Fortún, J.; Roilides, E.; Saliba, F.; Lortholary, O.; Muñoz, P.; Grossi, P.; CuencaEstrella, M. Invasive fungal infections in solid organ transplant recipients. Clin Microbiol Infect 2014, 20, 27-48, https://doi.org/10.1111/1469-0691.12660.

5. Bongomin, F.; Gago, S.; Oladele, R.O.; Denning, D.W. Global and Multi-National Prevalence of Fungal Diseases-Estimate Precision. J Fungi (Basel) 2017, 3, https://doi.org/10.3390/jof3040057.

6. Sabino, R.; Simões, H.; Veríssimo, C. Molecular Detection of Aspergillus: Application of a Real-Time PCR Multiplex Assay in Tissue Samples. J Fungi (Basel) 2020, 6, https://doi.org/10.3390/jof6010011.

7. Zhang, H.; Zhu, A. Emerging Invasive Fungal Infections: Clinical Features and Controversies in Diagnosis and Treatment Processes. Infect Drug Resist 2020, 13, 607-615, https://doi.org/10.2147/idr.S237815.

8. Barańska, M.; Kroll-Balcerzak, R.; Gil, L.; Rupa-Matysek, J.; Komarnicki, M. Successful treatment of pulmonary candidiasis and aspergillosis in patient with refractory Hodgkin lymphoma using micafungin case study and brief literature review. Cent Eur $J$ Immunol 2017, 42, 111-115, https://doi.org/10.5114/ceji.2016.65893

9. Tan, B.H.; Chakrabarti, A.; Patel, A.; Chua, M.M.M.; Sun, P.L.; Liu, Z.; Rotjanapan, P.; Li, R.; Wahyuningsih, R.; Chayakulkeeree, M.; Chen, Y.C. Clinicians' challenges in managing patients with invasive fungal diseases in seven Asian countries: An Asia Fungal Working Group (AFWG) Survey. Int $J$ Infect Dis 2020, 95, 471-480, https://doi.org/10.1016/j.jiid.2020.01.007.

10. Drgona, L.; Khachatryan, A.; Stephens, J.; Charbonneau, C.; Kantecki, M.; Haider, S.; Barnes, R. Clinical and economic burden of invasive fungal diseases in Europe: focus on pre-emptive and empirical treatment of Aspergillus and Candida species. Eur $J$ Clin Microbiol Infect Dis 2014, 33, 7-21, https://doi.org/10.1007/s10096-013-1944-3

11. Kidd, S.E.; Chen, S.C.; Meyer, W.; Halliday, C.L. A New Age in Molecular Diagnostics for Invasive Fungal Disease: Are We Ready? Front Microbiol 2019, 10, https://doi.org/10.3389/fmicb.2019.02903

12. Arvanitis, M.; Anagnostou, T.; Fuchs, B.B.; Caliendo, A.M.; Mylonakis, E. Molecular and nonmolecular diagnostic methods for invasive fungal infections. Clin Microbiol Rev 2014, 27, 490-526, https://doi.org/10.1128/cmr.00091-13.

13. Wagner, K.; Springer, B.; Pires, V.P.; Keller, P.M. Molecular detection of fungal pathogens in clinical specimens by $18 \mathrm{~S}$ rDNA high-throughput screening in comparison to ITS PCR and culture. Sci Rep 2018, 8, https://doi.org/10.1038/s41598-018-25129-w. 
14. Sanguinetti, M.; Posteraro, B.; Beigelman-Aubry, C.; Lamoth, F.; Dunet, V.; Slavin, M.; Richardson, M.D. Diagnosis and treatment of invasive fungal infections: looking ahead. J Antimicrob Chemother 2019, 74, ii27-ii37, https://doi.org/10.1093/jac/dkz041.

15. Kozel, T.R.; Wickes, B. Fungal diagnostics. Cold Spring Harb Perspect Med 2014, 4, https://doi.org/10.1101/cshperspect.a019299.

16. Craw, P.; Balachandran, W. Isothermal nucleic acid amplification technologies for point-of-care diagnostics: a critical review. Lab Chip 2012, 12, 2469-2486, https://doi.org/10.1039/c2lc40100b.

17. Obande, G.A.; Banga Singh, K.K. Current and Future Perspectives on Isothermal Nucleic Acid Amplification Technologies for Diagnosing Infections. Infect Drug Resist 2020, 13, 455-483, https://doi.org/10.2147/idr.S217571.

18. Endo, S.; Komori, T.; Ricci, G.; Sano, A.; Yokoyama, K.; Ohori, A.; Kamei, K.; Franco, M.; Miyaji, M.; Nishimura, K. Detection of gp43 of Paracoccidioides brasiliensis by the loop-mediated isothermal amplification (LAMP) method. FEMS Microbiol Lett 2004, 234, 93-97, https://doi.org/10.1016/j.femsle.2004.03.015.

19. Tatibana, B.T.; Sano, A.; Uno, J.; Kamei, K.; Igarashi, T.; Mikami, Y.; Miyaji, M.; Nishimura, K.; Itano, E.N. Detection of Paracoccidioides brasiliensis gp43 gene in sputa by loop-mediated isothermal amplification method. J Clin Lab Anal 2009, 23, 139-143, https://doi.org/10.1002/jcla.20304.

20. Trabasso, P.; Matsuzawa, T.; Fagnani, R.; Muraosa, Y.; Tominaga, K.; Resende, M.R.; Kamei, K.; Mikami, Y.; Schreiber, A.Z.; Moretti, M.L. Isolation and drug susceptibility of Candida parapsilosis sensu lato and other species of C. parapsilosis complex from patients with blood stream infections and proposal of a novel LAMP identification method for the species. Mycopathologia 2015, 179, 53-62, https://doi.org/10.1007/s11046-014-9830-9.

21. Noguchi, H.; Iwase, T.; Omagari, D.; Asano, M.; Nakamura, R.; Ueki, K.; Shinozuka, K.; Kaneko, T.; Tonogi, M.; Ohki, H. Rapid detection of Candida albicans in oral exfoliative cytology samples by loopmediated isothermal amplification. J Oral Sci 2017, 59, 541-547, https://doi.org/10.2334/josnusd.16-0717.

22. Goodarzi, M.; Shahhosseiny, M.H.; Bayat, M.; Hashemi, S.J.; Ghahri, M. Comparison between molecular methods (PCR vs LAMP) to detect Candida albicans in bronchoalveolar lavage samples of suspected tuberculosis patients. Microbiology Research 2018, 8, https://doi.org/10.4081/mr.2017.7306

23. Inácio, J.; Flores, O.; Spencer-Martins, I. Efficient identification of clinically relevant Candida yeast species by use of an assay combining panfungal loop-mediated isothermal DNA amplification with hybridization to species-specific oligonucleotide probes. Journal of clinical microbiology 2008, 46, 713-720, https://doi.org/10.1128/JCM.00514-07.

24. Kasahara, K.; Ishikawa, H.; Sato, S.; Shimakawa, Y.; Watanabe, K. Development of multiplex loopmediated isothermal amplification assays to detect medically important yeasts in dairy products. FEMS Microbiol Lett 2014, 357, 208-216, https://doi.org/10.1111/1574-6968.12512.

25. Nakayama, T.; Yamazaki, T.; Yo, A.; Tone, K.; Mahdi Alshahni, M.; Fujisaki, R.; Makimura, K. Detection of Fungi from an Indoor Environment using Loop-mediated Isothermal Amplification (LAMP) Method. Biocontrol Sci 2017, 22, 97-104, https://doi.org/10.4265/bio.22.97.

26. Yamamoto, M.; Alshahni, M. M.; Tamura, T.; Satoh, K.; Iguchi, S.; Kikuchi, K.; Mimaki, M.; Makimura, K. Rapid Detection of Candida auris Based on Loop-Mediated Isothermal Amplification (LAMP). J Clin Microbiol 2018, 56, https://doi.org/10.1128/jcm.00591-18.

27. Tang, Q.; Tian, S.; Yu, N.; Zhang, X.; Jia, X.; Zhai, H.; Sun, Q.; Han, L. Development and Evaluation of a Loop-Mediated Isothermal Amplification Method for Rapid Detection of Aspergillus fumigatus. $J$ Clin Microbiol 2016, 54, 950-955, https://doi.org/10.1128/jcm.01751-15.

28. Storari, M.; von Rohr, R.; Pertot, I.; Gessler, C.; Broggini, G.A. Identification of ochratoxin A producing Aspergillus carbonarius and A. niger clade isolated from grapes using the loop-mediated isothermal amplification (LAMP) reaction. J Appl Microbiol 2013, 114, 1193-1200, https://doi.org/10.1111/jam.12139.

29. Yu, L.S.; Rodriguez-Manzano, J.; Malpartida-Cardenas, K.; Sewell, T.; Bader, O.; Armstrong-James, D.; Fisher, M.C.; Georgiou, P. Rapid and Sensitive Detection of Azole-Resistant Aspergillus fumigatus by Tandem Repeat Loop-Mediated Isothermal Amplification. J Mol Diagn 2019, 21, 286-295, https://doi.org/10.1016/j.jmoldx.2018.10.004.

30. Lucas, S.; da Luz Martins, M.; Flores, O.; Meyer, W.; Spencer-Martins, I.; Inácio, J. Differentiation of Cryptococcus neoformans varieties and Cryptococcus gattii using CAP59-based loop-mediated isothermal DNA amplification. Clin Microbiol Infect 2010, 16, 711-714, https://doi.org/10.1111/j.14690691.2009.02919.x.

31. Matsuzawa, T.; Tanaka, R.; Horie, Y.; Gonoi, T.; Yaguchi, T. Development of rapid and specific molecular discrimination methods for pathogenic emericella species. Nihon Ishinkin Gakkai Zasshi 2010, 51, 109-116, https://doi.org/10.3314/jjmm.51.109.

32. Scheel, C.M.; Zhou, Y.; Theodoro, R.C.; Abrams, B.; Balajee, S.A.; Litvintseva, A.P. Development of a loop-mediated isothermal amplification method for detection of Histoplasma capsulatum DNA in clinical samples. J Clin Microbiol 2014, 52, 483-488, https://doi.org/10.1128/jcm.02739-13.

33. Zatti, M.D.S.; Arantes, T.D.; Fernandes, J.A.L.; Bay, M.B.; Milan, E.P.; Naliato, G.F.S.; Theodoro, R.C. Loop-mediated Isothermal Amplification and nested PCR of the Internal Transcribed Spacer (ITS) for 
Histoplasma capsulatum detection. PLoS Negl Trop Dis $\quad$ 2019, 13 , https://doi.org/10.1371/journal.pntd.0007692.

34. Sun, J.; Li, X.; Zeng, H.; Xie, Z.; Lu, C.; Xi, L.; de Hoog, G.S. Development and evaluation of loop-mediated isothermal amplification (LAMP) for the rapid diagnosis of Penicillium marneffei in archived tissue samples. FEMS Immunol Med Microbiol 2010, 58, 381-388, https://doi.org/10.1111/j.1574-695X.2010.00647.x.

35. Uemura, N.; Makimura, K.; Onozaki, M.; Otsuka, Y.; Shibuya, Y.; Yazaki, H.; Kikuchi, Y.; Abe, S.; Kudoh, S. Development of a loop-mediated isothermal amplification method for diagnosing Pneumocystis pneumonia. J Med Microbiol 2008, 57, 50-57, https://doi.org/10.1099/jmm.0.47216-0.

36. Singh, P.; Singh, S.; Mirdha, B.R.; Guleria, R.; Agarwal, S.K.; Mohan, A. Evaluation of Loop-Mediated Isothermal Amplification Assay for the Detection of Pneumocystis jirovecii in Immunocompromised Patients. Mol Biol Int 2015, 2015, https://doi.org/10.1155/2015/819091.

37. Ishikawa, H.; Kasahara, K.; Sato, S.; Shimakawa, Y.; Watanabe, K. Simple and rapid method for the detection of Filobasidiella neoformans in a probiotic dairy product by using loop-mediated isothermal amplification. Int J Food Microbiol 2014, 178, 107-112, https://doi.org/10.1016/j.ijfoodmicro.2014.03.008.

38. Zhou, J.; Liao, Y.; Li, H.; Lu, X.; Han, X.; Tian, Y.; Chen, S.; Yang, R. Development of a loop-mediated isothermal amplification assay for rapid detection of Trichosporon asahii in experimental and clinical samples. Biomed Res Int 2015, 2015, https://doi.org/10.1155/2015/732573.

39. Sun, J.; Najafzadeh, M.J.; Vicente, V.; Xi, L.; de Hoog, G S. Rapid detection of pathogenic fungi using loopmediated isothermal amplification, exemplified by Fonsecaea agents of chromoblastomycosis. J Microbiol Methods 2010, 80, 19-24, https://doi.org/10.1016/j.mimet.2009.10.002.

40. Niessen, L.; Gräfenhan, T.; Vogel, R.F. ATP citrate lyase 1 (acl1) gene-based loop-mediated amplification assay for the detection of the Fusarium tricinctum species complex in pure cultures and in cereal samples. Int J Food Microbiol 2012, 158, 171-185, https://doi.org/10.1016/j.ijfoodmicro.2012.06.021.

41. Niessen, L.; Vogel, R.F. Detection of Fusarium graminearum DNA using a loop-mediated isothermal amplification (LAMP) assay. Int J Food Microbiol 2010, 140, 183-191, https://doi.org/10.1016/j.ijfoodmicro.2010.03.036.

42. Denschlag, C.; Rieder, J.; Vogel, R.F.; Niessen, L. Real-time loop-mediated isothermal amplification (LAMP) assay for group specific detection of important trichothecene producing Fusarium species in wheat. International journal of food microbiology $\mathbf{2 0 1 4}, \quad 177, \quad$ 117-127, https://doi.org/10.1016/j.ijfoodmicro.2014.02.010.

43. Luo, J.; Vogel, R.F.; Niessen, L. Development and application of a loop-mediated isothermal amplification assay for rapid identification of aflatoxigenic molds and their detection in food samples. International journal of food microbiology 2012, 159, 214-224, https://doi.org/10.1016/j.ijfoodmicro.2012.08.018.

44. Luo, J.; Vogel, R.F.; Niessen, L. Rapid detection of aflatoxin producing fungi in food by real-time quantitative loop-mediated isothermal amplification. Food Microbiol 2014, 44, 142-148, https://doi.org/10.1016/j.fm.2014.06.004.

45. Hayashi, N.; Minato, T.; Kanai, K.; Ikushima, S.; Yoshida, S.; Tada, S.; Taguchi, H.; Ogawa, Y. Differentiation of species belonging to Saccharomyces sensu stricto using a loop-mediated isothermal amplification method. Journal of the American Society of Brewing Chemists 2009, 67, 118-126, https://doi.org/10.1094/ASBCJ-2009-0309-01.

46. Widjojoatmodjo, M.N.; Borst, A.; Schukkink, R.A.; Box, A.T.; Tacken, N.M.; Van Gemen, B.; Verhoef, J.; Top, B.; Fluit, A.C. Nucleic acid sequence-based amplification (NASBA) detection of medically important Candida species. J Microbiol Methods 1999, 38, 81-90, https://doi.org/10.1016/s0167-7012(99)00079-2.

47. Borst, A.; Leverstein-Van Hall, M.A.; Verhoef, J.; Fluit, A.C. Detection of Candida spp. in blood cultures using nucleic acid sequence-based amplification (NASBA). Diagn Microbiol Infect Dis 2001, 39, 155-160, https://doi.org/10.1016/s0732-8893(01)00211-5.

48. Loeffler, J.; Dorn, C.; Hebart, H.; Cox, P.; Magga, S.; Einsele, H. Development and evaluation of the nuclisens basic kit NASBA for the detection of RNA from Candida species frequently resistant to antifungal drugs. Diagn Microbiol Infect Dis 2003, 45, 217-220, https://doi.org/10.1016/s0732-8893(02)00510-2.

49. Loeffler, J.; Hebart, H.; Cox, P.; Flues, N.; Schumacher, U.; Einsele, H. Nucleic acid sequence-based amplification of Aspergillus RNA in blood samples. J Clin Microbiol 2001, 39, 1626-1629, https://doi.org/10.1128/jcm.39.4.1626-1629.2001.

50. Yoo, J.H.; Choi, J.H.; Choi, S.M.; Lee, D.G.; Shin, W.S.; Min, W.S.; Kim, C.C. Application of nucleic acid sequence-based amplification for diagnosis of and monitoring the clinical course of invasive aspergillosis in patients with hematologic diseases. Clin Infect Dis 2005, 40, 392-398, https://doi.org/10.1086/427284.

51. Yoo, J.H.; Choi, S.M.; Lee, D.G.; Park, S.H.; Choi, J.H.; Kwon, E.Y.; Shin, W.S. Comparison of the realtime nucleic acid sequence-based amplification (RTi-NASBA) with conventional NASBA, and galactomannan assay for the diagnosis of invasive aspergillosis. J Korean Med Sci 2007, 22, 672-676, https://doi.org/10.3346/jkms.2007.22.4.672.

52. Zhao, Y.; Park, S.; Warn, P.; Shrief, R.; Harrison, E.; Perlin, D.S. Detection of Aspergillus fumigatus in a rat model of invasive pulmonary aspergillosis by real-time nucleic acid sequence-based amplification. J Clin Microbiol 2010, 48, 1378-1383, https://doi.org/10.1128/jcm.02214-09. 
53. Zhao, Y.; Park, S.; Kreiswirth, B.N.; Ginocchio, C.C.; Veyret, R.; Laayoun, A.; Troesch, A.; Perlin, D.S. Rapid real-time nucleic Acid sequence-based amplification-molecular beacon platform to detect fungal and bacterial bloodstream infections. J Clin Microbiol 2009, 47, 2067-2078, https://doi.org/10.1128/jcm.0223008.

54. Park, C.; Kwon, E.Y.; Shin, N.Y.; Choi, S.M.; Kim, S.H.; Park, S.H.; Lee, D.G.; Choi, J.H.; Yoo, J.H. Evaluation of nucleic acid sequence based amplification using fluorescence resonance energy transfer (FRET-NASBA) in quantitative detection of Aspergillus 18S rRNA. Med Mycol 2011, 49, 73-79, https://doi.org/10.3109/13693786.2010.507604.

55. Wang, L.; He, Y.; Xia, Y.; Su, X.; Wang, H.; Liang, S. Retrospective comparison of nucleic acid sequencebased amplification, real-time PCR, and galactomannan test for diagnosis of invasive aspergillosis. $J$ Mol Diagn 2014, 16, 584-590, https://doi.org/10.1016/j.jmoldx.2014.05.001.

56. Brenier-Pinchart, M.P.; Abaibou, H.; Berendsen, T.; Szymanski, G.; Beghri, M.; Bailly, S.; Lasnet, F.; Thiebaut-Bertrand, A.; Mabilat, C.; Pelloux, H. Usefulness of pan-fungal NASBA test for surveillance of environmental fungal contamination in a protected hematology unit. Med Mycol 2014, 52, 433-437, https://doi.org/10.1093/mmy/myt017.

57. Du, L.; Xia, Y.; He, Y.; Pu, Q.; Hua, R.; Wu, W. Development and evaluation of enzyme-linked immunosorbent assay of nucleic acid sequence-based amplification for diagnosis of invasive aspergillosis. AMB Express 2016, 6, https://doi.org/10.1186/s13568-016-0266-0.

58. Zhou, X.; Kong, F.; Sorrell, T.C.; Wang, H.; Duan, Y.; Chen, S.C. Practical method for detection and identification of Candida, Aspergillus, and Scedosporium spp. by use of rolling-circle amplification. J Clin Microbiol 2008, 46, 2423-2427, https://doi.org/10.1128/jcm.00420-08.

59. Kaocharoen, S.; Wang, B.; Tsui, K.M.; Trilles, L.; Kong, F.; Meyer, W. Hyperbranched rolling circle amplification as a rapid and sensitive method for species identification within the Cryptococcus species complex. Electrophoresis 2008, 29, 3183-3191, https://doi.org/10.1002/elps.200700903.

60. Trilles, L.; Wang, B.; Firacative, C.; Lazéra Mdos, S.; Wanke, B.; Meyer, W. Identification of the major molecular types of Cryptococcus neoformans and C. gattii by Hyperbranched rolling circle amplification. PLoS One 2014, 9, https://doi.org/10.1371/journal.pone.0094648.

61. Furuie, J.L.; Sun, J.; do Nascimento, M.M.; Gomes, R.R.; Waculicz-Andrade, C.E.; Sessegolo, G.C.; Rodrigues, A.M.; Galvão-Dias, M.A.; de Camargo, Z.P.; Queiroz-Telles, F.; Najafzadeh, M.J.; de Hoog, S.G.; Vicente, V.A. Molecular identification of Histoplasma capsulatum using rolling circle amplification. Mycoses 2016, 59, 12-19, https://doi.org/10.1111/myc.12426.

62. Kong, F.; Tong, Z.; Chen, X.; Sorrell, T.; Wang, B.; Wu, Q.; Ellis, D.; Chen, S. Rapid identification and differentiation of Trichophyton species, based on sequence polymorphisms of the ribosomal internal transcribed spacer regions, by rolling-circle amplification. Journal of Clinical Microbiology 2008, 46, 11921199, https://doi.org/10.1128/JCM.02235-07.

63. Najafzadeh, M.J.; Sun, J.; Vicente, V.A.; de Hoog, G.S. Rapid identification of fungal pathogens by rolling circle amplification using Fonsecaea as a model. Mycoses 2011, 54, e577-582, https://doi.org/10.1111/j.1439-0507.2010.01995.x.

64. Hamzehei, H.; Yazdanparast, S.A.; Mohammad Davoudi, M.; Khodavaisy, S.; Golehkheyli, M.; Ansari, S.; de Hoog, G.S.; Badali, H. Use of rolling circle amplification to rapidly identify species of Cladophialophora potentially causing human infection. Mycopathologia 2013, 175, 431-438, https://doi.org/10.1007/s11046013-9630-7.

65. Sun, J.; Najafzadeh, M.J.; Zhang, J.; Vicente, V.A.; Xi, L.; de Hoog, G.S. Molecular identification of Penicillium marneffei using rolling circle amplification. Mycoses 2011, 54, e751-759, https://doi.org/10.1111/j.1439-0507.2011.02017.x.

66. Zhao, F.; Niu, L.; Yan, L.; Nong, J.; Wang, C.; Wang, J.; Gao, N.; Zhu, X.; Wu, L.; Zheng, F.; Hu, S. Establishment and application of multiple cross displacement amplification coupled with lateral flow biosensor (MCDA-LFB) for visual and rapid detection of Candida albicans in clinical samples. Frontiers in cellular and infection microbiology 2019, 9, https://doi.org/10.3389/fcimb.2019.00102.

67. Foster, S.J.; Monahan, B.J. Whole genome amplification from filamentous fungi using Phi29-mediated multiple displacement amplification. Fungal Genetics and Biology 2005, 42, 367-375, https://doi.org/10.1016/j.fgb.2005.01.013.

68. Jiang, X.; Dong, D.; Bian, L.; Zou, D.; He, X.; Ao, D.; Yang, Z.; Huang, S.; Liu, N.; Liu, W.; Huang, L. Rapid Detection of Candida albicans by Polymerase Spiral Reaction Assay in Clinical Blood Samples. Front Microbiol 2016, 7, https://doi.org/10.3389/fmicb.2016.00916.

69. Sakai, K.; Trabasso, P.; Moretti, M.L.; Mikami, Y.; Kamei, K.; Gonoi, T. Identification of fungal pathogens by visible microarray system in combination with isothermal gene amplification. Mycopathologia 2014, 178, 11-26, https://doi.org/10.1007/s11046-014-9756-2.

70. Deng, S.; de Hoog, G.S.; Pan, W.; Chen, M.; van den Ende, A.H.; Yang, L.; Sun, J.; Najafzadeh, M.J.; Liao, W.; Li, R. Three isothermal amplification techniques for rapid identification of Cladophialophora carrionii, an agent of human chromoblastomycosis. $J$ Clin Microbiol 2014, 52, 3531-3535, https://doi.org/10.1128/jcm.01033-14. 
71. Zhao, Y.; Paderu, P.; Railkar, R.; Douglas, C.; Iannone, R.; Shire, N.; Perlin, D.S. Blood Aspergillus RNA is a promising alternative biomarker for invasive aspergillosis. Med Mycol 2016, 54, 801-807, https://doi.org/10.1093/mmy/myw043

72. Cortez, K.J.; Roilides, E.; Quiroz-Telles, F.; Meletiadis, J.; Antachopoulos, C.; Knudsen, T.; Buchanan, W.; Milanovich, J.; Sutton, D.A.; Fothergill, A.; Rinaldi, M.G.; Shea, Y.R.; Zaoutis, T.; Kottilil, S.; Walsh, T.J. Infections caused by Scedosporium spp. Clin Microbiol Rev 2008, 21, 157-197, https://doi.org/10.1128/cmr.00039-07

73. Kaneko, T.; Makimura, K.; Abe, M.; Shiota, R.; Nakamura, Y.; Kano, R.; Hasegawa, A.; Sugita, T.; Shibuya, S.; Watanabe, S.; Yamaguchi, H.; Abe, S.; Okamura, N. Revised culture-based system for identification of Malassezia species. J Clin Microbiol 2007, 45, 3737-3742, https://doi.org/10.1128/jcm.01243-07.

74. Walsh, T.J.; Gamaletsou, M.N.; McGinnis, M.R.; Hayden, R.T.; Kontoyiannis, D.P. Early clinical and laboratory diagnosis of invasive pulmonary, extrapulmonary, and disseminated mucormycosis (zygomycosis). Clinical Infectious Diseases 2012, 54, S55-S60, https://doi.org/10.1093/cid/cir868.

75. Becherer, L.; Borst, N.; Bakheit, M.; Frischmann, S.; Zengerle, R.; von Stetten, F. Loop-mediated isothermal amplification (LAMP)-review and classification of methods for sequence-specific detection. Analytical Methods 2020, 12, 717-746, https://doi.org/10.1039/C9AY02246E.

76. Ruhnke, M.; Schwartz, S. Recent developments in the management of invasive fungal infections in patients with oncohematological diseases. Ther Adv Hematol 2016, 7, 345-359, https://doi.org/10.1177/2040620716656381.

77. Gabaldón, T. Recent trends in molecular diagnostics of yeast infections: from PCR to NGS. FEMS Microbiol Rev 2019, 43, 517-547, https://doi.org/10.1093/femsre/fuz015.

78. Walker, F.M.; Hsieh, K. Advances in Directly Amplifying Nucleic Acids from Complex Samples. Biosensors (Basel) 2019, 9, https://doi.org/10.3390/bios9040117

79. Ala-Houhala, M.; Koukila-Kähkölä, P.; Antikainen, J.; Valve, J.; Kirveskari, J.; Anttila, V.J. Clinical use of fungal PCR from deep tissue samples in the diagnosis of invasive fungal diseases: a retrospective observational study. Clin Microbiol Infect 2018, 24, 301-305, https://doi.org/10.1016/j.cmi.2017.08.017.

80. Camp, I.; Manhart, G.; Schabereiter-Gurtner, C.; Spettel, K.; Selitsch, B.; Willinger, B. Clinical evaluation of an in-house panfungal real-time PCR assay for the detection of fungal pathogens. Infection 2020, 48, 345355, https://doi.org/10.1007/s15010-020-01395-7.

81. White, P.L.; Alanio, A.; Cruciani, M.; Gorton, R.; Millon, L.; Rickerts, V.; Barnes, R.A.; Donnelly, J.P.; Loeffler, J. Nucleic Acid Tools for Invasive Fungal Disease Diagnosis. Current Fungal Infection Reports 2020, 14, 76-88, https://doi.org/10.1007/s12281-020-00374-7.

82. Fuchs, S.; Lass-Flörl, C.; Posch, W. Diagnostic Performance of a Novel Multiplex PCR Assay for Candidemia among ICU Patients. J Fungi (Basel) 2019, 5, https://doi.org/10.3390/jof5030086. 